\title{
Abnormal Plasminogen
}

\author{
A HEREDITARY MOLECULAR ABNORMALITY FOUND \\ IN A PATIENT WITH RECURRENT THROMBOSIS
}

\author{
Nobuo Aoki, Masaaki Moroi, Yoichi Sakata, Nobuhiko Yoshida, \\ and Michio Matsuda, Department of Medicine and the Institute of Hematology, \\ Jichi Medical School, Yakushiji, Tochigi-Ken 329-04, Japan
}

\begin{abstract}
A B S T RACT A patient who suffered a recurring thrombosis over the last $15 \mathrm{yr}$ has been investigated. The only abnormality found in this patient was a significantly depressed level of plasminogen activity in plasma. In spite of the depressed plasminogen activity, the patient was found to have a normal level of plasminogen antigen concentration. It was calculated that the activity per milligram of plasminogen of the patient was approximately one-half the values of normal subjects. The same discrepancy between biological activity and antigen concentration was found in the other members of the kindred. A niece was found to have practically no plasminogen activity but possessed a normal concentration of plasminogen antigen. Both her parents were found to have approximately half the normal plasminogen activity and normal antigen levels. These studies suggested that the molecular abnormality was inherited as an autosomal characteristic, and the family members who had half the normal levels of activity with normal plasminogen antigen were heterozygotes whereas the one with practically no plasminogen activity was homozygote. Subsequent studies showed that the pattern of gel electrofocusing of purified plasminogen of the heterozygotes consisted of 10 normal bands and 10 additional abnormal bands, each of which had a slightly higher isoelectric point than each corresponding normal component. This indicates that plasminogen of the heterozygote is a mixture of normal and abnormal molecules in an approximately equal amount, which was substantiated by active site titration of purified plasminogen preparations obtained from the propositus and a normal individual. The gel electrofocusing
\end{abstract}

Portions of this work were presented at the annual meeting of the Japanese Society of Hematology, Kanazawa, Japan. 15 May 1977.

Received for publication 13 May 1977 and in revised form 27 December 1977. pattern of the homozygote consisted of abnormal bands only. The defect is a hereditary abnormality of plasminogen.

\section{INTRODUCTION}

Plasminogen is a zymogen in plasma that is converted to active protease plasmin by plasminogen activators released from various sources including vascular walls. This plasminogen-plasmin system is a major part of the fibrinolytic mechanism in vivo and is believed to play an important role in limiting the extent of fibrin deposition. The reduction of fibrinolytic activity, whatever the mechanism of the reduction may be, may provoke a thrombotic tendency by allowing the growth and development of thrombi after an initiating thrombotic event. This prediction is supported by reports of animal studies $(1,2)$, as well as by clinical reports (3-6), in which development of thromboembolism follows suppression of fibrinolytic activity by the administration of antifibrinolytic agents or the increase of natural inhibitors of fibrinolysis. Inadequate release of plasminogen activator resulting in reduced fibrinolytic activity is also thought to be an accelerating factor for the development of venous thrombosis (7). A thrombotic tendency caused by an impaired fibrinolysis due to a plasminogen deficiency, however, has not been documented. In the present study, a patient with recurring thrombosis was shown to have abnormally low plasminogen activity but normal levels of immunoreactive plasminogen. The abnormality of plasminogen was found to be inherited.

\section{METHODS}

Plasma. Blood was collected from antecubital veins into $1 / 10 \mathrm{vol}$ of $3.8 \%$ sodium citrate and was centrifuged at $2,000 \mathrm{~g}$ for $20 \mathrm{~min}$ to prepare plasma. Plastic syringes, centrifuge 
tubes, and storage containers were used. Plasma was stored at $-80^{\circ} \mathrm{C}$ until use.

Normal subjects. 23 normal adults served as controls for the study of plasminogen.

Patients with liver cirrhosis. Plasminogen from 15 patients with liver cirrhosis of varying severity was studied. The diagnosis was based on the pathological appearance of the tissue specimens obtained by liver biopsy performed under laparoscopy as well as on laboratory examinations.

Purification of plasminogen. Plasminogen was prepared from human fresh plasma or plasma that had been stored at $-80^{\circ} \mathrm{C}$ in $1 \mathrm{mM}$ protease inhibitor, phenylmethyl sulfonylfluoride (Sigma Chemical Co., St. Louis, Mo.). Plasma was first subjected to affinity chromatography according to the method of Brockway and Castellino (8). Plasminogen fractions I and II, which were eluted from lysine-coupled Sepharose were combined, and further purified by DEAESephadex chromatography (9).

Assay for plasminogen activity. Plasma plasminogen was assayed by the caseinolytic method (10). Plasma $(0.5 \mathrm{ml})$ was mixed and incubated with $0.5 \mathrm{ml}$ of $1 / 6 \mathrm{~N} \mathrm{HCl}$ for $15 \mathrm{~min}$ at room temperature to destroy plasmin inhibitor (11) and then neutralized with $0.5 \mathrm{ml}$ of $1 / 6 \mathrm{~N} \mathrm{NaOH}$ and $1 \mathrm{ml}$ of phosphate-buffered saline $(0.1 \mathrm{M}$ phosphate, $0.9 \% \mathrm{NaCl}, \mathrm{pH} 7.6)$. To plasma thus treated $0.5 \mathrm{ml}$ of $2,000 \mathrm{U} / \mathrm{ml}$ streptokinase (Varidase, Lederle Laboratories, Pearl River, N. Y.) was added together with $2 \mathrm{ml}$ of $5 \%$ casein (Hammarsten, AG Merck, Darmstadt, W. Germany). The mixture was incubated at $37^{\circ} \mathrm{C}$. After $2 \mathrm{~min} 2 \mathrm{ml}$ was withdrawn and mixed with $2 \mathrm{ml}$ of $15 \%$ trichloroacetic acid. This served as the control. After $62 \mathrm{~min}$ incubation of the original mixture a further $2-\mathrm{ml}$ sample was withdrawn and mixed with $2 \mathrm{ml}$ of $15 \%$ trichloroacetic acid. The mixtures were allowed to stand for $30 \mathrm{~min}$ at room temperature. The precipitates formed were removed by repeated centrifugation, and the optical density of each solution was measured at $280 \mathrm{~nm}$. The results were expressed in Remmert and Cohen casein units (12). The casein unit used in the present study, however, should be regarded as an arbitrary unit, because it was not calibrated against a CTA (Committee on Thrombolytic Agents) unit or an international standard in which the assay is carried out with $\alpha$-casein as a substrate $(13,14)$. To insure the results, $500 \mathrm{U} / \mathrm{ml}$ urokinase was also used instead of streptokinase. Both methods using streptokinase or urokinase gave nearly identical results.

A euglobulin fraction of plasma was also used for the assay of plasminogen. Plasma $(0.5 \mathrm{ml})$ was diluted with $9.5 \mathrm{ml}$ of cold $0.016 \%$ acetic acid, and left in an ice-water bath for 30 min. The precipitate formed was collected by centrifugation, dissolved with $2.5 \mathrm{ml}$ of phosphate-buffered saline, and subjected to the assay for plasminogen by the method described above for acid-treated plasma. This method gave values roughly $10 \%$ less than those obtained by activating acidtreated plasma. The results obtained by streptokinase activation of acid-treated plasma were used for plasminogen activity unless otherwise indicated.

Purified plasminogen was assayed also by an esterolytic method. Plasminogen was first activated in $25 \%$ glycerol solution with $2,000 \mathrm{U} / \mathrm{ml}$ streptokinase at $25^{\circ} \mathrm{C}$ for $5 \mathrm{~min}$. Plasmin formed was assayed by the potentiometric method (15) using $N$-acetyl-glycyl-L-lysine methyl ester (Protein Research Foundation, Osaka, Japan) as a substrate. $1 \mathrm{U}$ was defined as the activity catalyzing the hydrolysis of $1 \mu \mathrm{mol}$ of substrate/min.

Assay for plasminogen concentration. Plasminogen (antigen) concentration was measured by the single radial immunodiffusion technique of Mancini et al. (16). $10 \mu \mathrm{l}$ of antigen solution (purified plasminogen or plasma) was placed in a hole (2.4-mm diameter) in the agarose layer $(0.8 \%$ agarose in barbital buffer, pH $8.6,0.05 \mathrm{M}$, containing $0.05 \%$ sodium azide, and $1.8-\mathrm{mm}$ thickness) containing $0.5 \%$ of antiplasminogen antiserum on a glass plate, and was left in a moist chamber for $72 \mathrm{~h}$. Diameters of the resulting rings of immuneprecipitates were measured. Dilutions of known amounts of purified plasminogen were made with $0.9 \% \mathrm{NaCl}$ containing $3 \%$ bovine albumin and used for calibration. There was a linear relationship between the diameter ${ }^{2}$ of the rings and amounts of antigen applied up to $50 \mathrm{mg} / 100 \mathrm{ml}$ (Fig. 1). Purified plasminogen used for calibration was prepared by the method of Brockway and Castellino (8) and was a single component when analyzed by sodium dodecyl sulfate polyacrylamide gel electrophoresis (17). The antiplasminogen antiserum used was the one described previously (18), and was monospecific when analyzed by immunoelectrophoresis as well as by double immunodiffusion technique on agarose. Protein concentration of purified plasminogen used for calibration was determined by measuring the absorbance of the plasminogen solution $(\mathrm{pH} 7.4)$ at $280 \mathrm{~nm}$ and converting absorbance to protein concentration using $E_{1 \mathrm{~cm}}{ }_{1 \%}=17.0$ for purified plasminogen (19).

Active site titration. Active sites of plasmin were titrated with $p$-nitrophenyl $p^{\prime}$-guanidinobenzoate $\mathrm{HCl}$ (ICN Nutritional Biochemicals Div., International Chemical Nuclear Corp., Cleveland, Ohio) according to the method described by Chase and Shaw (20).

Amino-terminal analysis. The amino-terminal group of plasminogen molecules was analyzed using dansyl chloride (21). Dansylated amino acids were identified by thinlayer chromatography on polyamide sheets (21).

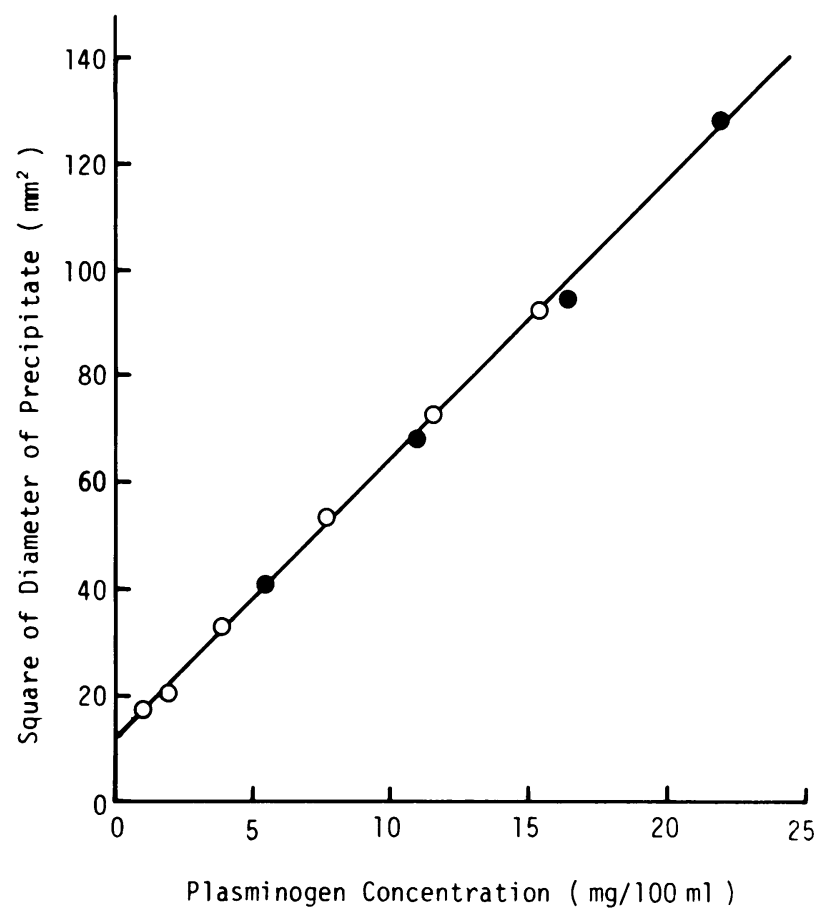

FIGURE 1 Linear relationship between squares of each diameter of the precipitin rings and the concentrations of plasminogen applied in a single radial immunodiffusion. Closed circles, purified plasminogen. Open circles, normal standard plasma. 
Gel electrophoresis. Sodium dodecyl sulfate $(\mathrm{SDS})^{1}$ polyacrylamide gel electrophoresis was performed with $5 \%$ polyacrylamide gels according to the method of Weber and Osborn (17).

Analytical gel electrofocusing. Analytical thin-layer gel electrofocusing in polyacrylamide $(5 \%)$ gel was performed with Ampholine (LKB Produkter AB, Bromma, Sweden) (6.7\%), pH range 5-8.5, using LKB Multiphor apparatus (LKB Produkter AB, Bromma, Sweden) according to the methods described by Vesterberg (22) and those in the instruction manual supplied by the company. Electrophoresis was carried out at $400 \mathrm{~V}$ for $1 \mathrm{~h}$ and then at $900 \mathrm{~V}$ for an additional $2 \mathrm{~h}$ at $4^{\circ} \mathrm{C}$.

Preparative isoelectric focusing. Separations by isoelectric focusing methods were carried out according to methods described by Vesterberg (23), with the LKB model 8100 jacketed column (440-ml capacity). Fractions of $3.8 \mathrm{ml}$ were collected by gravity flow at a regulated flow rate of $1.5 \mathrm{ml} / \mathrm{min}$. The protein content and plasminogen antigen content of each fraction were determined from its absorbance at $280 \mathrm{~nm}$ and by the single radial immunodiffusion technique described above, respectively. Plasminogen activity was assayed by an esterolytic method. The $\mathrm{pH}$ of each fraction was measured at room temperature using a Radiometer TTTIa pH-meter (Radiometer Co., Copenhagen, Denmark).

Assay for concentration of proteinase inhibitors. Concentrations of proteinase inhibitors in plasma such as $\alpha_{2^{-}}$ macroglobulin, $\alpha_{1}$-antitrypsin, and $\alpha_{2}$-plasmin inhibitor $\left(\alpha_{2} \mathrm{PI}\right)$ were determined by single radial immunodiffusion technique (16). Partigen plates (Behring-Werke AG, Marburg/ Lahn, West Germany) were used for $\alpha_{2}$-macroglobulin and $\alpha_{1}$-antitrypsin. $\alpha_{2}$ PI was measured as described above for measurement of plasminogen antigen concentration using anti- $\alpha_{2}$ PI antiserum (24) and purified $\alpha_{2} \mathrm{PI}(24)$ as a reference.

Antithrombin III assay. Antithrombin III activity of

${ }^{1}$ Abbreviations used in this paper: $\alpha_{2} \mathrm{PI}, \alpha_{2}$-plasmin inhibitor; pI, isoelectric point; SDS, sodium dodecyl sulfate. plasma was assayed by the method of Monkhouse (25) and expressed as a percent of normal pooled plasma.

Antithrombin III (antigen) concentration was measured by the single radial immunodiffusion technique using Partigen plates (Behringwerke AG).

Routine coagulation and fibrinolysis tests. Prothrombin time was performed by the method of Quick (26). Activated partial thromboplastin time was performed by the method described by Denson (27). Fibrinogen content of plasma was assayed by the method of Ratnoff and Menzie (28). Platelets were counted by a Coulter Counter (Coulter Electronics Inc., Hialeah, Fla.). Platelet aggregation studies were performed by the turbidimetric method of Born (29) using an Aggregometer (Bryston Co., Canada). Concentrations of fibrinogen/fibrin degradation products were estimated by hemagglutination inhibition test of Merskey et al. (30).

Euglobulin clot lysis time was performed by the method of von Kaulla and Schultz (31).

Statistical analyses. Comparisons of the samples were performed using Cochran's modification of Student's $t$ analysis (32), and other statistical analyses were done by the standard methods.

\section{RESULTS}

Case history. The propositus (subject II-10 in Fig. 2) is a 31-yr-old male who had been in excellent health until the age of 15 , when he developed severe thrombophlebitis in his left leg after sustaining a bruise on his left calf. Thrombophlebitis recurred several times over the next $2 \mathrm{yr}$, and secondary varicose veins gradually developed in his left leg. At the age of 19 he developed thrombophlebitis in his right leg, which recurred within a year. Varicose veins gradually developed in his right leg as well. At the age of 21 , he suffered a sudden onset of tinnitus, dizziness, headache, nausea, vomiting, and transient unconscious-
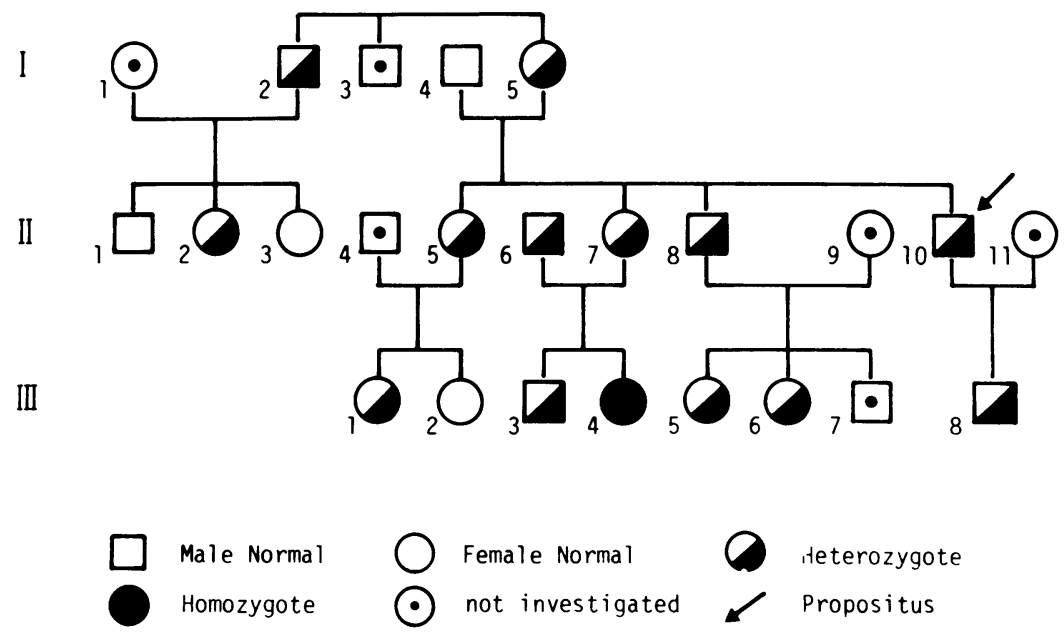

FIGURE 2 Pedigree of family Y with abnormal plasminogen. Each subject may be located in the pedigree by a roman numeral indicating generation and an arabic numeral indicating position within the generation. Subjects possessing approximately $5-6 \mathrm{U} / \mathrm{mg}$ plasminogen were considered to be heterozygotes. Subject III-4 was considered to be homozygote because of her very low activity per milligram plasminogen $(<1 \mathrm{U} / \mathrm{mg})$. An arrow indicates the propositus. 
ness. After admission to a hospital, intracranial hypertension was diagnosed. The cause of intracranial hypertension was not determined in spite of extensive examinations. The possibility of intracranial venous thrombosis was considered. Intracranial hypertension gradually subsided. During this hospitalization, he suddenly suffered dyspnea, slight chest pain, and cough with hemoptysis, and pulmonary embolism was diagnosed. He also suffered superficial thrombophlebitis caused by local trauma from intravenous drip infusion of various solutions. At the age of 25 he suffered the sudden onset of chest pain, dyspnea, and hemoptysis. Signs of thrombophlebitis of both legs were noted. Pulmonary infarction was diagnosed by chest X-ray, pulmonary angiography, hemodynamic studies, and lung perfusion scan using ${ }^{131}$ I-labeled macroaggregated albumin. At the age of 27 he suffered cramping abdominal pain and was hospitalized. He underwent laparotomy; approximately the upper half of the small intestine was found to be swollen and discolored, and the superior mesenteric vein was occluded with thrombi which extended to the portal vein. Hemorrhagic ascites were noted. The mesenteric artery appeared to be free of thrombi. The affected part of the small intestine was resected. Histological examination of the resected intestine showed markedly dilated veins packed with red cells and partly with fresh thrombi. There was no thickness of the intima. There were no findings suggestive of angitis such as fibrinoid necrosis, leukocyte infiltration, or disruption of the elastica.

At the age of 30 he suffered generalized urticaria associated with aggrevation of thrombophlebitis of both legs. In July of the same year, 1976, he was first admitted to Jichi Medical School Hospital with a diagnosis of acute abdomen and underwent laparotomy. A perforated duodenal ulcer was found, and a gastrojejunostomy was performed. Histological examination showed a chronic duodenal ulcer that was perforated and the presence of intimal fibrosis of small veins in the major omentum suggestive of the presence of organized thrombi. After convalescence the patient was subjected to a thorough investigation to find the cause of his thrombotic tendency. In November 1976, prophylactic treatment with oral anticoagulant warfarin was instituted.

Family history. Because of the striking thrombotic tendency of the patient, his family members were subjected to study except for one of his maternal uncles and one of his nephews, neither of whom were available.

None of these family members reported any episode suggestive of thrombosis. Two sisters had had two miscarriages each. There was no history of consanguinity.

Laboratory evaluations. The propositus was evaluated for evidence of coagulation/fibrinolysis abnor- malities. The results are presented in Table I. The only abnormality found was a low activity of plasminogen. This low plasminogen activity was also found when assayed by urokinase activation of acid-treated plasma as well as urokinase or streptokinase activation of euglobulin fraction. The initiation of anticoagulant therapy did not affect the level of plasminogen activity and it remained constantly low. Other laboratory tests, including liver function tests, serum electrophoresis, C-reactive protein, antinuclear antibody, and other parameters of the presence of inflammatory processes or collagen disease, were all normal or negative.

Evaluation of plasminogen. The plasminogen abnormality found in the propositus was further investigated. Plasminogen caseinolytic activities and antigen concentrations in plasma samples obtained from the propositus on three different occasions over 3 mo during which there was no sign of thrombosis were $0.69,0.72,0.67 \mathrm{U} / \mathrm{ml}$ and $14.6,13.4,13.5 \mathrm{mg} / 100$ $\mathrm{ml}$, respectively.

When 23 normal, healthy Japanese adults were studied, plasminogen caseinolytic activities and antigen concentrations were found to be $1.68 \pm 0.14$ $($ mean $\pm \mathrm{SE}) \mathrm{U} / \mathrm{ml}$ and $15.7 \pm 1.3($ mean $\pm \mathrm{SE}) \mathrm{mg} / 100$ $\mathrm{ml}$, respectively. From these values, it was concluded that plasminogen activity in plasma of the propositus was abnormally low although the concentration of plasminogen antigen was within the normal range. Caseinolytic activity per milligram plasminogen (antigen) in plasma of the propositus

TABLE I

Coagulation/Fibrinolysis Studies in the Propositus

\begin{tabular}{|c|c|c|}
\hline Studies & Propositus & Normal or control \\
\hline Prothrombin time, $s$ & 12 & $11-12$ \\
\hline $\begin{array}{l}\text { Activated partial } \\
\text { thromboplastin }\end{array}$ & & \\
\hline time, $s$ & 25 & $24-32$ \\
\hline \multicolumn{3}{|l|}{ Antithrombin III } \\
\hline Activity, \% & 95 & $90-110$ \\
\hline $\begin{array}{l}\text { Antigen concentra- } \\
\text { tion, } m g / 100 \mathrm{ml}\end{array}$ & 27 & $17-30$ \\
\hline Fibrinogen, $\mathrm{mg} / 100 \mathrm{ml}$ & 190 & $150-400$ \\
\hline Platelet count, per $\mu l$ & 150,000 & $150,000-400,000$ \\
\hline Platelet aggregation & Normal & \\
\hline $\begin{array}{l}\text { Plasminogen activity, } \\
\quad U / m l\end{array}$ & 0.69 & $1.3-2.1$ \\
\hline Euglobulin lysis & & \\
\hline $\begin{array}{l}\text { time, } h \\
\alpha_{2} \text {-Plasmin inhibitor, }\end{array}$ & 5 & $2-4$ \\
\hline $\begin{array}{l}m g / 100 \mathrm{ml} \\
\alpha_{2} \text {-Macroglobulin, }\end{array}$ & 5.05 & $5-7$ \\
\hline $\begin{array}{c}m g / 100 \mathrm{ml} \\
\alpha_{1} \text {-Antitrypsin }\end{array}$ & 210 & $150-300$ \\
\hline$m g / 100 \mathrm{ml}$ & 215 & $150-300$ \\
\hline
\end{tabular}


was calculated to be $5.03 \mathrm{U} / \mathrm{mg}$ on average, which is approximately half the normal control value $(10.68 \pm 0.79 \mathrm{U} / \mathrm{mg})$. Caseinolytic activities as well as antigen concentrations of plasminogen in plasma of the family members were also examined. The results are presented in Fig. 2 and Table II. Subjects whose caseinolytic activity per milligram plasminogen was below the normal mean minus $3 \mathrm{SE}(8.31 \mathrm{U} / \mathrm{mg})$ were provisionally regarded as abnormal. The father and paternal uncles of the propositus were all normal, and the abnormality appeared to have been inherited from the maternal side. Caseinolytic activity per milligram plasminogen of the abnormal family members, except for one niece (III-4), was calculated to be $5.39 \pm 0.51$ $\mathrm{U} / \mathrm{mg}$ (mean $\pm \mathrm{SE}, n=12$ ), which is approximately half that of normal control. The difference between the means of normal control and the abnormal members was significant $(P<0.001)$.

To make sure that the low caseinolytic activity of plasminogen in plasma of the abnormal family members was not due to impaired liver function, the relationship between caseinolytic activity and antigen concentration was studied in patients with liver cirrhosis in whom production of plasminogen in liver is reported to be reduced, and the result was compared with that of the abnormal family members (Fig. 3). In liver cirrhosis, caseinolytic activity is reduced in proportion to the decrease of antigen concentration, and the ratio of caseinolytic activity to antigen con-

TABLE II

Plasminogen Activity in Family $Y$

\begin{tabular}{rccr}
\hline Pedigree position* $^{*}$ & \multicolumn{3}{c}{ Plasminogen antigen } \\
\hline & U/ml & $m g / 100 m l$ & U/mg \\
I -2 & 0.68 & 13.8 & 4.93 \\
-4 & 1.65 & 16.2 & 10.19 \\
-5 & 0.78 & 15.3 & 5.10 \\
II -1 & 1.48 & 15.3 & 9.67 \\
-2 & 1.29 & 21.8 & 5.90 \\
-3 & 1.79 & 15.8 & 11.30 \\
-5 & 0.87 & 17.0 & 5.12 \\
-6 & 1.04 & 18.3 & 5.68 \\
-7 & 0.96 & 19.2 & 5.00 \\
-8 & 0.95 & 19.2 & 4.95 \\
-10 & 0.67 & 13.5 & 4.96 \\
III -1 & & 16.7 & 5.01 \\
-2 & 0.84 & 16.0 & 10.73 \\
-3 & 1.72 & 13.4 & 6.17 \\
-4 & 0.83 & 16.4 & 0.61 \\
-5 & 0.10 & 15.3 & 5.97 \\
-6 & 0.91 & 15.5 & 6.19 \\
-8 & 0.96 & 12.7 & 5.35 \\
& 0.68 & &
\end{tabular}

* Pedigree position refers to the pedigree in Fig. 2.

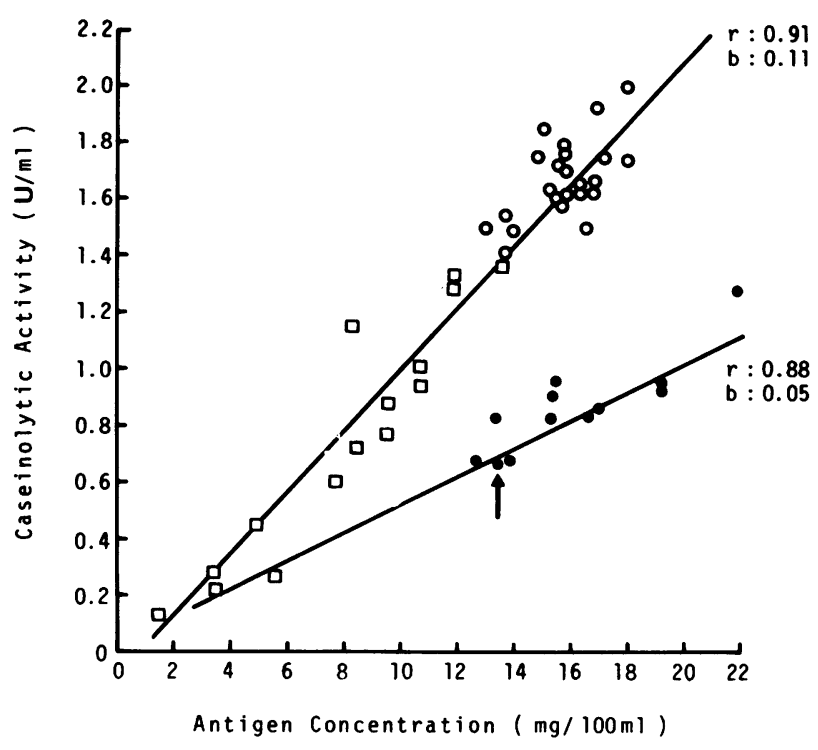

FIGURE 3 Relationship between caseinolytic activity and antigen concentration of plasminogen. $O$, Normal subjects; $\square$, patients with liver cirrhosis; $\boldsymbol{O}$, affected family members except subject III-4; $r$, correlation coefficient; $b$, regression coefficient. An arrow indicates the propositus.

centration remains approximately the same as that of normal healthy controls (Fig. 3). This is represented in Fig. 3 by a good correlation $(r=0.91)$ observed between caseinolytic activity and antigen concentration in plasma of a group consisting of patients with liver cirrhosis and normal subjects. In the abnormal family members, the ratio of caseinolytic activity to antigen concentration was quite different from that of a group of the normal control and liver cirrhosis, and was approximately half that of normal control and liver cirrhosis. This is represented in Fig. 3 by the difference of sample regression coefficient: 0.114 \pm 0.0098 (95\% confidence limits) for normal control and liver cirrhosis, and $0.053 \pm 0.0212$ for the abnormal family members.

One of the nieces (III-4) of the propositus was found to have exceptionally low caseinolytic activity of plasminogen $(0.1 \mathrm{U} / \mathrm{ml})$ when examined by either way of streptokinase or urokinase activation of acidtreated plasma or euglobulin fraction, although the level of her immunoreactive plasminogen $(16.4 \mathrm{mg} / 100$ $\mathrm{ml})$ was within normal limits $(15.7 \pm 1.3 \mathrm{mg} / 100 \mathrm{ml})$. Caseinolytic activity per milligram plasminogen of this 5-yr-old girl was calculated to be 0.61 , which was about $1 / 18$ of the average normal control $(10.68 \mathrm{U} /$ $\mathrm{mg}$ ) and about $1 / 9$ of the average value $(5.39 \mathrm{U} / \mathrm{mg})$ of other abnormal family members. Consequently, plasminogen of her father was also investigated and was found like her mother to have the same low degree of caseinolytic activity per milligram plasminogen $(5.68 \mathrm{U} / \mathrm{mg})$ as that $(5.39 \pm 0.51 \mathrm{U} / \mathrm{mg})$ found 
in the propositus and his abnormal family members other than III-4. These results indicate that subject III-4 is a homozygote, and her parents, as well as other abnormal family members, are heterozygotes.

Molecular abnormality of plasminogen. Plasma samples of the propositus, his mother, and a normal healthy control were separately subjected to affinity chromatography on lysine-coupled Sepharose. Protein elution profiles are shown in Fig. 4. The peak of absorbance of plasminogen fraction I (Glu-1-form) which was eluted first was generally lower than that of fraction II (Glu-2-form) in normal control, whereas in the case of the propositus and his mother the peak of absorbance of fraction I was higher than that of fraction II.

Plasminogen fractions I and II were separately concentrated by lyophilization. Each lyophilized material was dissolved with $2 \mathrm{ml}$ of distilled water, dialyzed against Tris $0.05 \mathrm{M}-\mathrm{NaCl} 0.15 \mathrm{M}, \mathrm{pH} 7.4$, and subsequently analyzed for activity and antigen concentra-

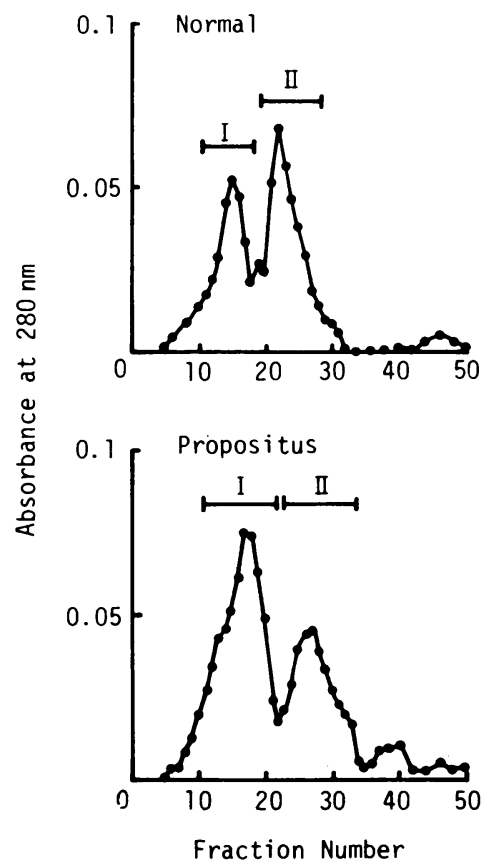

FIGURE 4 Elution profiles of affinity chromatography of plasminogen on lysine-coupled Sepharose. $10 \mathrm{ml}$ of fresh plasma of normal control or the propositus was applied to a column of lysine-coupled Sepharose $(1.4 \times 5.9 \mathrm{~cm})$ equilibrated with Tris-saline $(0.15 \mathrm{M} \mathrm{NaCl}, 0.05 \mathrm{M}$ Tris- $\mathrm{HCl}$, $1 \mathrm{mM}$ EDTA, pH 7.4). The column was washed first with $50 \mathrm{ml}$ of Tris-saline and then with $150 \mathrm{ml}$ of Tris-saline containing $2 \mathrm{M} \mathrm{NaCl}$ at a How rate at $8 \mathrm{ml} / \mathrm{h}$. After washing, the adsorbed proteins were eluted with a linear gradient with the reservoir containing $100 \mathrm{ml}$ of $25 \mathrm{mM}$ 6-aminohexanoic acid in Tris-saline and the mixing chamber containing $100 \mathrm{ml}$ of Tris-saline. The flow rate was maintained at $8 \mathrm{ml} / \mathrm{h}$, and fractions of $3.6 \mathrm{ml}$ each were collected. The procedures were carried out at $4^{\circ} \mathrm{C}$. Fractions I and II, indicated by brackets, were separately concentrated and subjected to analyses.
TABLE III

Analyses of Plasminogen Fractions by Affinity Chromatography

\begin{tabular}{lccc}
\hline \multicolumn{1}{c}{ Fraction } & $\begin{array}{c}\text { Caseinolytic } \\
\text { activity }\end{array}$ & $\begin{array}{c}\text { Antigen } \\
\text { concentration }\end{array}$ & $\begin{array}{c}\text { Specific } \\
\text { activity* }\end{array}$ \\
\hline Propositus & $U / m l$ & $m g / 100 m l$ & $U / m g$ \\
$\quad$ I & $1.14(1.19) \ddagger$ & 16.8 & $6.8(7.1)$ \\
$\quad$ II & $1.43(1.44)$ & 19.2 & $7.5(7.5)$ \\
Normal control & & & \\
$\quad$ I & $2.73(3.31)$ & 17.7 & $15.4(18.7)$ \\
II & $2.82(3.70)$ & 17.2 & $16.4(21.5)$ \\
\hline
\end{tabular}

* Activity per milligram antigen protein.

‡ Esterolytic activity in parentheses.

tion. The results are presented in Table III, which shows that both caseinolytic and esterolytic activities per milligram plasminogen in each fraction of the propositus were less than half (roughly $40 \%$ ) of those of corresponding fractions of normal control. These fractions were combined and analyzed by SDS gel electrophoresis and immunoelectrophoresis. No difference of patterns of SDS gel electrophoresis and immunoelectrophoresis was observed between plasminogen of the propositus and that of the normal control, and the results of SDS gel electrophoresis are presented in Fig. 5.

Plasminogen of a normal control and that of the propositus were activated separately with urokinase, and each plasmin formed was analyzed by SDS gel electrophoresis (Fig. 5). The patterns show the characteristic heavy and light chains of plasmin, and no significant difference was observed between the samples. The specific activities of the plasmin of normal control and the propositus were 16 and 7.3 casein $\mathrm{U} / \mathrm{mg}$ protein, respectively.

Active sites of plasmin of normal control and the propositus were titrated with $p$-nitrophenyl $p^{\prime}$-guanidinobenzoate $\mathrm{HCl}$. Plasminogen preparations of a normal control and the propositus at three different concentrations ranging from 0.2 to $1.2 \mathrm{mg} / \mathrm{ml}$ were separately activated with $10,000 \mathrm{U} / \mathrm{ml}$ streptokinase at $25^{\circ} \mathrm{C}$ for $1 \mathrm{~h}$ in $0.05 \mathrm{M}$ Veronal (Wako Pure Chemical Industries, Osaka, Japan) buffer containing 25\% glycerol ( $\mathrm{pH}$ 8.3). The plasmin formed was then titrated for active sites. Active site concentrations of normal control and the propositus were found to be 0.83 and 0.36 active sites on average per mole of protein, respectively.

The fractions obtained by another run of the chromatography were combined and further purified by DEAE-Sephadex chromatography. DEAE-Sephadex chromatography was necessary to remove contaminants often revealed by SDS gel electrophoresis in the preparations after the affinity chromatography. 


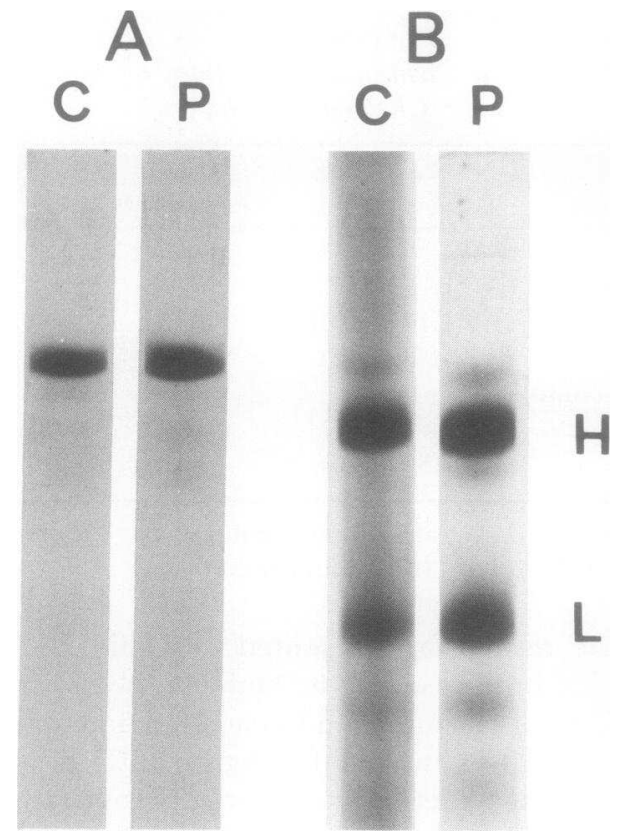

FIGURE 5 SDS polyacrylamide gel electrophoresis of plasminogen and plasmin. $\mathrm{P}$ and $\mathrm{C}$ represent plasminogen/ plasmin of the propositus and those of normal control, respectively. Plate A: approximately $15 \mu \mathrm{g}$ of plasminogen was applied to each gel column. Plate B: $400 \mu \mathrm{g} / \mathrm{ml}$ of plasminogen was activated with $1,000 \mathrm{U} / \mathrm{ml}$ of urokinase at $37^{\circ} \mathrm{C}$ for $20 \mathrm{~min}$ in Tris-saline $(0.05 \mathrm{M}$ Tris- $\mathrm{HCl}, 0.15 \mathrm{M} \mathrm{NaCl}, 1 \mathrm{mM}$ EDTA, $\mathrm{pH} 7.4$ ) containing $0.02 \mathrm{M}$ lysine and $15 \%$ glycerol. Approximately $20 \mu \mathrm{g}$ of the resulting plasmin/plasminogen mixture was subjected to electrophoresis after reduction with $5 \%$ $\beta$-mercaptoethanol.

DEAE-Sephadex chromatography of the plasminogen preparation originated from Cohn's fraction III results in separation of two fractions; namely, DE-A fraction containing native plasminogen and DE-B fraction containing partially degraded forms (9). In the present study, the preparation after the affinity chromatography of plasma was applied to DEAE chromatography and the plasminogen was eluted almost exclusively as DE-A fraction. Little was eluted as DE-B fraction. The yield of plasminogen in DE-A fraction was approximately $70 \%$. The specific activities of a normal control and the propositus were 17.4 and 8.0 casein $\mathrm{U} / \mathrm{mg}$ protein, respectively. These were approximately $10 \%$ higher than the specific activities of the materials before DEAE chromatography. The purified plasminogen preparations thus obtained were analyzed by amino-terminal analysis and thinlayer gel electrofocusing. The amino-terminal group was identified as glutamic acid. No lysine was detected as an amino-terminal group.

Remarkable differences of thin-layer gel electrofocusing pattern were constantly observed between plasminogen of the propositus or his mother and that of a normal control. As shown in Fig. 6A, the pattern of plasminogen of the normal control consisted of 10 clearly separated major bands, whereas the pattern of plasminogen of the propositus and his mother contained an additional 10 bands, each of which was located to the basic side and closely parallel to each corresponding normal band, giving an appearance of splitting each normal band. When the plasminogen of the propositus or his mother was run very closely side by side with normal plasminogen, one of each pair of bands located to the acidic side fused with each corresponding normal band. This may indicate that the plasminogen is heterozygous and is a mixture of normal components and abnormal components with slightly higher isoelectric point $(\mathrm{pI})$ values than normals. In contrast to these results obtained with heterozygous plasminogen, the pattern of electrofocusing of homozygous plasminogen (III-4) consisted of 10 instead of 20 bands of heterozygous plasminogen and the pattern itself was similar to that of normal control as shown in Fig. $6 \mathrm{~B}$. The pattern of the mixture of homozygous and normal plasminogens in approximately equal amounts was similar to that of heterozygous plasminogen (Fig. $6 \mathrm{~B}$ ), indicating that all the components of homozygous plasminogen separated by electrofocusing represent the abnormal components of heterozygous plasminogen.

Fractionation of plasminogen by isoelectric focusing. Plasminogen of the propositus was fractionated by preparative isoelectric focusing methods. Plasmino-

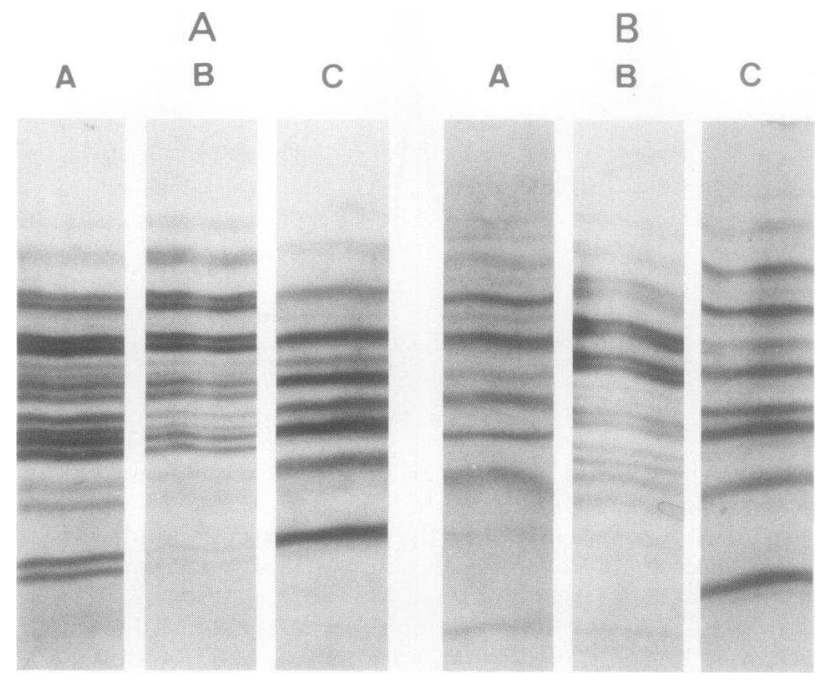

Figure 6 Analytical thin-layer gel electrofocusing of plasminogen. Approximately $30 \mu \mathrm{g}$ each of plasminogen was applied. The $\mathrm{pH}$ gradient from 5 to 9 was from the top to the bottom. Plate A: analysis of heterozygotes; A, propositus; B, mother of propositus; C, normal control. Plate B: analysis of homozygote; A, homozygote (III-4); B, mixture of homozygote and normal; C, normal control. 
gen (50 mg) prepared by affinity chromatography on lysine-Sepharose and without DEAE chromatography was electrofocused in the $440-\mathrm{ml}$ column in $4 \% \mathrm{Am}$ pholine, $\mathrm{pH}$ range $5-7$, at $900 \mathrm{~V}$ for $72 \mathrm{~h}$ at $4^{\circ} \mathrm{C}$. The absorbance $\mathrm{pH}$ patterns are shown in Fig. 7. Six protein peaks were obtained with $\mathrm{pI}$ ranging from $\mathrm{pH}$ 6 to 6.7. However, each protein peak was rather broad, and separation of abnormal components from normal components was not visible. Consequently, the fractions in the range of $\mathrm{pH} 5.9-6.8$ (fraction no. 35-73) were combined and directly rerun by isoelectric focusing in the $440-\mathrm{ml}$ column at $900 \mathrm{~V}$ for $144 \mathrm{~h}$ at $4^{\circ} \mathrm{C}$. The concentration of Ampholine was approximately $1.4 \%$. The essential part of the absorbance $\mathrm{pH}$ pattern together with plasminogen activity and antigen concentration of each fraction are shown in Fig. 8. There were three pairs of protein peaks. The peak of each pair that had the lower $\mathrm{pI}$ value was associated equally with plasminogen antigen and activity. The other peak, the one that had the higher $\mathrm{pI}$ value, was associated with plasminogen antigen but not associated with much plasminogen activity. The former peaks may represent the normal components, whereas most of the protein comprising the latter peaks may be abnormal components. The difference of $\mathrm{pI}$ values between normal and abnormal peaks was 0.03-0.04.

\section{DISCUSSION}

The case presented in this paper suggests that low fibrinolytic activity caused by the low level of plasminogen activity predisposes to the thrombotic tendency once the initial thrombotic event has occurred. The severe thrombophlebitis the propositus suffered after trauma at age 15 initiated a series of thrombotic events over the subsequent $15 \mathrm{yr}$. This propensity

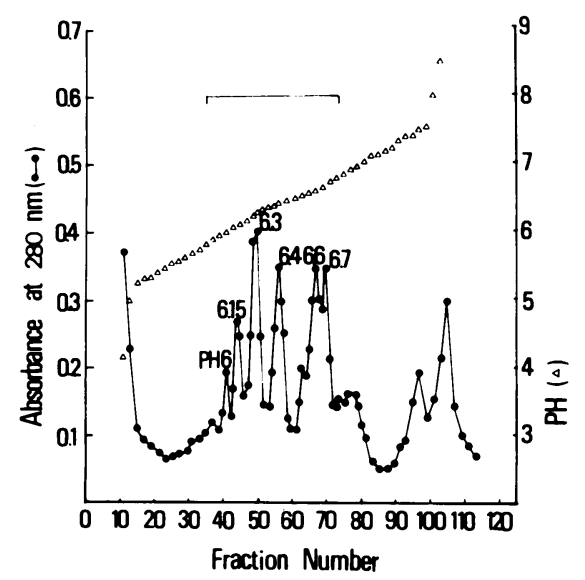

FIGURE 7 Isoelectric focusing absorbance $\mathrm{pH}$ pattern of plasminogen of propositus. The fractions indicated by a bracket were combined and rerun by isoelectric focusing as shown in Fig. 8. For details, see text.

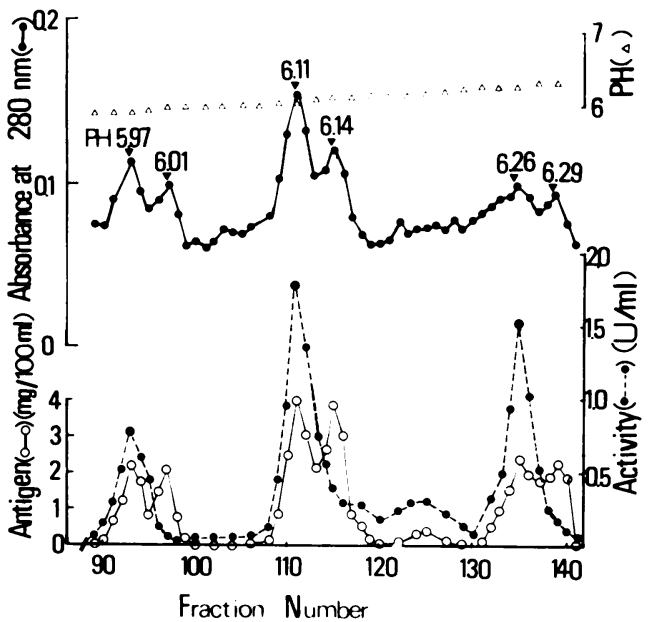

FIgure 8 Isoelectric focusing of the combined fractions indicated by a bracket in Fig. 7. Isoelectric forms with pI values 6.4, 6.6, and 6.7 in Fig. 7 were not separated and formed a large single peak in the region of fraction numbers $160-180$ which is the edge region of the linear $\mathrm{pH}$ gradient, and are not shown in this figure. For details, see text.

for thrombosis may be at least partly due to decreased fibrinolytic potential which works as a protecting mechanism against the development of thrombosis. Another factor contributing to the recurrence of thrombosis in this patient may have been the lack of sufficient treatment with anticoagulant therapy he had received for the initial several thrombotic events, which might have allowed the spreading of thrombi and accelerated development of varicose veins. Varicose veins in turn became loci where activation of clotting occurred and helped the development of a hypercoagulable state. A venous anomaly favoring the development of thrombi also cannot be ruled out in this patient. A low level of plasminogen activity cannot be the sole cause of the development of thrombosis as evidenced by the fact that none of the affected members in the kindred other than the propositus experienced any thrombotic events. It is interesting, however, that plasminogen activity of the propositus was the lowest among the family members (Fig. 3 and Table II) and was approximately $40 \%$ of the mean of normal control.

The inference that a deficiency of a protecting mechanism against development of thrombosis cannot cause thrombosis by itself may be applied also to antithrombin III deficiency, which is known to constitute a thrombotic tendency although not all the individuals who have the defect develop thrombosis. Many of the affected individuals developed thrombosis after such triggering events as childbirth, surgery, or trauma after adolescence (33-37).

Subject III-4 who is now age 6 was found to possess practically no plasminogen activity but has thus far 
experienced no thrombotic event. The only physical abnormality she now has is a tendency to form induration in subcutaneous tissues after minor trauma. Whether or not this has anything to do with deficiency of plasminogen is not known at the present time.

The biochemical defect in family $\mathrm{Y}$ is apparently transmitted by an autosomal gene and has an incomplete recessive character. The defect found was the production of altered plasminogen molecules. In the affected members in the kindred, biological activity per unit of quantity of plasminogen determined by immunochemical method was found to be nearly half of a normal control. Furthermore, the analyses by electrofocusing of plasminogen purified from plasma of heterozygotes or homozygotes suggested that the plasminogen in the heterozygotes is a mixture of normal molecules and altered nonfunctioning molecules in about equal amounts. Active-site titration of plasmin of a normal control and the propositus suggested that plasminogen of the propositus consisted of abnormal and normal molecules in a ratio of 57 and $43 \%$, respectively. These results are in accordance with the generally accepted rule of autosomal genes that the heterozygote produces one-half normal protein and one-half mutant protein.

Plasminogen analyzed was a mixture of Glu-1- and Glu-2-forms. Normal control plasminogen consisted of 10 major components with different pI values (Fig. 6). Summaria et al. (38) also found a total of 10 isoelectric forms with different $\mathrm{pI}$ values in Glu-1-plus Glu-2-forms by acrylamide gel electrophoresis in the presence of $\epsilon$-aminocaproic acid. Multiple molecular isoelectric forms of plasminogen were explained by the difference of their sialic acid content (39). Abnormal plasminogen molecules also consisted of 10 major components, each of which had a slightly higher pI value than each corresponding normal component. When heterozygous plasminogen was fractionated by preparative isoelectric focusing methods with $\mathrm{pH}$ range $5-7$, six isoelectric forms with pI values $6,6.15$, $6.3,6.4,6.6$, and 6.7 were obtained (Fig. 7). These isoelectric forms are essentially the same as those obtained by Wallen and Wiman (9), and the four acidic forms among these six forms were identified as Gluplasminogen $(9,40)$. These fractions of Glu-plasminogen were electrofocused again using the narrower $\mathrm{pH}$ range 5.9-6.8. By this second isoelectric focusing, each of three isoelectric forms with pI values $6,6.15$, and 6.3 in Fig. 7 was separated into two components (Fig. 8). The difference of $\mathrm{pI}$ values of the two components of each pair was rather constant, being $0.03-$ 0.04 . The acidic component of each pair was associated with plasminogen activity as well as plasminogen antigen, whereas the basic component of each pair was associated with no or less plasminogen activity but possessed plasminogen antigen (Fig. 8). The latter components may represent nonfunctioning, altered components of heterozygous plasminogen, whose pI values are higher than each corresponding normal component by $0.03-0.04$. Plasminogen of the homozygote seems to be composed of abnormal components only (Fig. $6 \mathrm{~B}$ ), but detailed studies on homozygote plasminogen have not yet been possible due to a lack of material because the homozygote is a 6 -yr-old girl. The question as to whether the altered molecular forms resulted from an amino acid substitution or from the variance of carbohydrate content is the interesting subject to be solved in the future studies.

Apart from the structural alteration, it is interesting to note that an amount of Glu-2-form was less than that of Glu-1-form in plasma of the affected individuals (Fig. 4) in contrast to normal control. This is reflected in patterns of electrofocusing as the comparatively low density of basic bands as seen particularly in the middle pattern of Fig. $6 \mathrm{~A}$.

Subject II-2 was found to be heterozygote in spite of the relatively high plasminogen activity $(1.29 \mathrm{U} / \mathrm{ml})$. This is ascribed to abnormally increased amounts of plasminogen antigen in plasma $(21.8 \mathrm{mg} / 100 \mathrm{ml} \mathrm{vs}$. the normal control values $15.7 \pm 1.3 \mathrm{mg} / 100 \mathrm{ml}$ ). A compensatory mechanism which accelerates the production of plasminogen might be operating in this particular subject.

Subject II-6, who is heterozygote and the father of subject III-4 (homozygote), came from a family that has lived for generations in the same region (Utsunomiya) as family $\mathrm{Y}$. This might suggest the possibility of the prevalence of the gene responsible for abnormal plasminogen at least in this particular geographical region. An alternative is that this coupling of heterozygotes was indeed the unusual chance of the rare gene. The development of a rapid screening method for the detection of the abnormal plasminogen would make it possible to elucidate the frequency and distribution of this gene.

\section{ACKNOWLEDGMENTS}

We would like to acknowledge the cooperation of Doctors S. Kano, M. Sumiya, and H. Seki and the technical assistance of Mrs. K. Yagizawa. We are thankful to Doctor S. Iwanaga, Protein Research Institute, Osaka University, for allowing one of us (M. M.) to carry out amino-terminal analysis in his laboratory. We are grateful to Doctor K. C. Robbins, Michael Reese Medical Center, Chicago, Ill., for comments and critical reading of the manuscript.

This work was supported by Scientific Research grants from the Ministry of Education of the Government of Japan.

\section{REFERENCES}

1. Ashford, T. P., M. C. Weinstein, and D. G. Freiman 1968. The role of the intrinsic fibrinolytic system in the prevention of stasis thrombosis in small veins: an electron microscopic study. Am. J. Pathol. 52: 1117-1127.

2. Kato, N., M. Morimatsu, K. Tanaka, and A. Horie. 1970, 
Effects of trans-4-aminomethylcyclohexane carboxylic acid as an antifibrinolytic agent on arterial wall and experimental atherosclerotic lesions in rabbits. Thromb. Diath. Haemorrh. 24: 85-99.

3. Nilsson, I. M., H. Krook, N. H. Sternby, E. Soderberg, and N. Soderstrom. 1961. Severe thrombotic disease in a young man with bone marrow and skeletal changes and with a high content of inhibitor in the fibrinolytic system. Acta Med. Scand. 169: 323-337.

4. Naeye, R. L. 1961. Thrombotic disorders with increased levels of antiplasmin and antiplasminogen. $N$. Engl. J. Med. 265: 867-871.

5. Brakman, P., E. R. Mohler, and T. Astrup. 1966. A group of patients with impaired fibrinolytic system and selective inhibition of tissue activator-induced fibrinolysis. Scand. J. Haematol. 3: 389-398.

6. McKay, D. G., and G. Müller-Berghaus. 1967. Therapeutic implications of disseminated intravascular coagulation. Am. J. Cardiol. 20: 392-410.

7. Isacson, S., and I. M. Nilsson. 1972. Defective fibrinolysis in blood and vein walls in recurrent "idiopathic" venous thrombosis. Acta Chir. Scand. 138: 313-319.

8. Brockway, W. J., and F. J. Castellino. 1972. Measurement of the binding of antifibrinolytic amino acids to various plasminogens. Arch. Biochem. Biophys. 151: 194-199.

9. Wallen, P., and B. Wiman. 1972. Characterization of human plasminogen. II. Separation and partial characterization of different molecular forms of human plasminogen. Biochim. Biophys. Acta. 257: 122-134.

10. McNicol, G. P., and A. S. Douglas. 1976. Plasminogen assay in plasma. In Human Blood Coagulation, Haemostasis and Thrombosis. R. Biggs, editor. Blackwell Scientific Publications, Ltd. Oxford. 2nd edition. 574-726.

11. Alkjaersig, N., A. P. Fletcher, and S. Sherry. 1959. The mechanism of clot dissolution by plasmin.J. Clin. Invest. 38: $1086-1095$.

12. Remmert, L. F., and P. P. Cohen. 1949. Partial purification and properties of a proteolytic enzyme of human serum. J. Biol. Chem. 181: 431-448.

13. Robbins, K. C., and L. Summaria. 1970. Human plasminogen and plasmin. Methods Enzymol. 19: 184-199.

14. Johnson, A. J., D. L. Kline, and N. Alkjaersig. 1969. Assay methods and standard preparations for plasmin, plasminogen and urokinase in purified systems, 1967-1968. Thromb. Diath. Haemorrh. 21: 259-272.

15. Walsh, K. A., and P. E. Wilcox. 1970. Serine proteases. Methods Enzymol. 19: 31-41.

16. Mancini, G., A. O. Carbonara, and J. F. Heremans. 1965. Immunochemical quantitation of antigens by single radial immunodiffusion. Int. J. Immunochem. 2: 235-254.

17. Weber, K., and M. Osborn. 1969. The reliability of molecular weight determinations by dodecyl sulfate-polyacrylamide gel electrophoresis. J. Biol. Chem. 244: 4406-4412.

18. Aoki, N., M. Moroi, M. Matsuda, and K. Tachiya. 1977. The behavior of $\alpha_{2}$-plasmin inhibitor in fibrinolytic states. J. Clin. Invest. 60: 361-369.

19. Barlow, G. H., L. Summaria, and K. C. Robbins. 1969 Molecular weight studies on human plasminogen and plasmin at the microgram level. J. Biol. Chem. 244: $1138-1141$.

20. Chase, T., Jr., and E. Shaw. 1970. Titration of trypsin, plasmin, and thrombin with $p$-Nitrophenyl $p^{\prime}$-guanidinobenzoate $\mathrm{HCl}$. Methods Enzymol. 19: 20-27.

21. Gray, W. R. 1972. End-group analysis using dansyl chloride. Methods Enzymol. 25: 121-138.
22. Vesterberg, O. 1972. Isoelectric focusing of proteins in polyacrylamide gels. Biochim. Biophys. Acta. 257: 11-19.

23. Vesterberg, O. 1971. Isoelectric focusing of proteins. Methods Enzymol. 22: 389-412.

24. Moroi, M., and N. Aoki. 1976. Isolation and characterization of $\alpha_{2}$-plasmin inhibitor from human plasma. J. Biol. Chem. 251: 5956-5965.

25. Monkhouse, F. C. 1963. The influence of inorganic salts of plasma antithrombin activity. Thromb. Diath. Haemorrh. 9: 387-394.

26. Tocantins, L. M. 1964. Estimation of prothrombin (onestage method of Quick). In Blood Coagulation, Hemorrhage and Thrombosis. L. A. Tocantins and L. A. Kazal, editors. Grune \& Stratton, Inc., New York. 148-150.

27. Denson, K. W. E. 1976. Kaolin-cephalin clotting time. In Human Blood Coagulation, Haemostasis and Thrombosis. R. Biggs, editor. Blackwell Scientific Publications, Ltd., Oxford. 2nd edition. 677-679.

28. Ratnoff, O. D., and C. Menzie. 1951. A new method for the determination of fibrinogen in small samples of plasma. J. Lab. Clin. Med. 37: 316-320.

29. Born, G. V. R. 1962. Aggregation of blood platelets by adenosine diphosphate and its reversal. Nature (Lond.). 194: 927-929.

30. Merskey, C., G. J. Kleiner, and A. J. Johnson. 1966. Quantitative estimation of split products of fibrinogen in human serum, relation to diagnosis and treatment. Blood. 28: $1-18$.

31. von Kaulla, K. N., and R. L. Schultz. 1958. Methods for the evaluation of human fibrinolysis. Am. J. Clin. Pathol. 29: 104-111.

32. Snedecor, G. W., and W. G. Cochran. 1967. Statistical Methods. Iowa State University Press, Ames, Iowa. 6th edition. 114-116.

33. Egeberg, O. 1967. Inherited antithrombin deficiency causing thrombophilia. Thromb. Diath. Haemorrh. 17: $176-187$.

34. von Kaulla, E., and K. N. von Kaulla. 1972. Deficiency of antithrombin III activity associated with hereditary thrombosis tendency. J. Med. (Westbury). 3: 349-358.

35. van der Meer, J., E. A. Stoepman-van Dalen, and J. M. S Jansen. 1973. Antithrombin-III deficiency in a Dutch family. J. Clin. Pathol. (Lond.). 26: 532-538.

36. Marciniak, E., C. H. Farley, and P. A. DeSimone. 1974 Familial thrombosis due to antithrombin III deficiency. Blood. 43: 219-231.

37. Sas, G., G. Blasko, D. Banhegyi, J. Jako, and L. A. Palos. 1974. Abnormal antithrombin III (antithrombin III 'Budapest') as a cause of a familial thrombophilia. Thromb. Diath. Haemorrh. 32: 105-115.

38. Summaria, L., F. Spitz, L. Arzadon, I. G. Boreisha, and K. C. Robbins. 1976. Isolation and characterization of the affinity chromatography forms of human Glu- and Lysplasminogens and plasmins. J. Biol. Chem. 251: 36933699.

39. Castellino, F. J., G. E. Siefring, Jr., J. M. Sodetz, and R. K. Bretthauer. 1973. Amino terminal amino acid sequences and carbohydrate of the two major forms of rabbit plasminogen. Biochem. Biophys. Res. Commun. 53: $845-851$.

40. Summaria, L., L. Arzadon, P. Bernabe, K. C. Robbins, and G. H. Barlow. 1973. Characterization of the $\mathrm{NH}_{2-}$ terminal glutamic acid and $\mathrm{NH}_{2}$-terminal lysine forms of human plasminogen isolated by affinity chromatography and isoelectric focusing methods. J. Biol. Chem. 248: 2984-2991. 